\title{
Out-of-hospital cardiac arrests in nursing homes and primary care facilities in Pirkanmaa, Finland
}

Heidi Kangasniemi ${ }^{\dagger a, b, d^{*}}$, Piritta Setälä ${ }^{\dagger b}$, Heini Huhtala ${ }^{c}$, Antti Kämäräinen ${ }^{b}$, Ilkka Virkkunen ${ }^{\text {a, b }}$, Esa Jämsen $^{\mathrm{d}}$, Arvi Yli-Hankala ${ }^{\mathrm{d}, \mathrm{e}}$, Sanna Hoppu ${ }^{\mathrm{b}}$

${ }^{a}$ Research and Development Unit, FinnHEMS Ltd, WTC Helsinki Airport, Lentäjäntie 3, 01530, Vantaa, Finland

${ }^{\mathrm{b}}$ Emergency Medical Services, Tampere University Hospital, P.O. Box 2000, FI-33521 Tampere, Finland

${ }^{\mathrm{c}}$ Faculty of Social Sciences, University of Tampere, P.O. Box 100, FI-33014 Tampere, Finland

${ }^{\mathrm{d}}$ Faculty of Medicine and Life Sciences, University of Tampere, FI-33014 Tampere, Finland

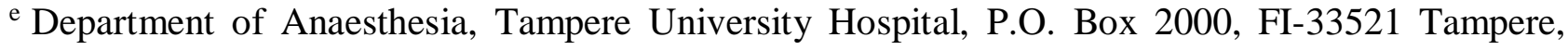
Finland

${ }^{\dagger}$ Equal contribution

$*$

Heidi Kangasniemi, MD, Research and Development Unit, FinnHEMS Ltd, WTC Helsinki Airport, Lentäjäntie 3, 01530, Vantaa, Finland and Emergency Medical Services, Tampere University Hospital, PO Box 2000, FI-33521 Tampere, Finland. Phone: +358 3311611 or +358 293005000 ; Fax: +358 9 85657339; Email: kangasniemi.heidi.j@student.uta.fi

Short title: OHCAs in nursing homes in Finland

Word count abstract: 247

Word count article: 2437

Tables and figures: 2 tables, 1 figure

Number of references: 32

Clinicaltrials.gov number: NCT00951704. https://clinicaltrials.gov/ct2/show/NCT00951704.

\section{Conflicts of interest}

The authors confirm there are no conflicts of interest to report. 


\section{ABSTRACT}

Background: Dispatching Emergency Medical Services to treat patients with deteriorating health in nursing homes and primary care facilities is common in Finland. We examined the cardiac arrest patients to describe this phenomenon. We had a special interest in patients for whom cardiopulmonary resuscitation was considered futile.

Methods: We conducted an observational study between 1 June 2013 and 31 May 2014 in the Pirkanmaa area. We included cases in which Emergency Medical Services participated in the treatment of cardiac arrest patients in nursing homes and primary care facilities.

Results: Emergency Medical Services attended to a total of 355 cardiac arrest patients, and 65 patients $(18 \%)$ met the inclusion criteria. The included patients were generally older than 65 years, but otherwise heterogeneous. Nineteen patients (29\%) had a valid do-not-attempt-resuscitation order, but paramedics were not informed about it in ten $(53 \%)$ of those cases. Eight (12\%) of the 65 patients survived to hospital admission and three (5\%) survived to hospital discharge with a neurologically favourable outcome. Two patients were alive 90 days after the cardiac arrest; both were younger than 70 years of age and had ventricular fibrillation as primary rhythm. There were no survivors in nursing homes.

Conclusions: The do-not-attempt-resuscitation orders were often unavailable during a cardiopulmonary resuscitation attempt. Although resuscitation attempts were futile for patients in nursing homes, some patients in primary care facilities demonstrated a favourable outcome after cardiac arrest. Emergency Medical Services seem to be able to recognise potential survivors and focus resources on their treatment. 


\section{Introduction}

Sudden cardiac arrest (CA) generally results in poor outcomes, as the survival to hospital discharge has been reported as only 7-8 \% ${ }^{1}$. Recently, some encouraging studies on out-of-hospital cardiac arrest (OHCA) have been published, that report increasing survival over time due to improvements in CA management ${ }^{2-5}$. Yet the survival rate among patients older than 80 years of age has not improved as much over time when compared to the rate among younger CA patients ${ }^{6}$. Better survival after CA is associated with cardiopulmonary resuscitation (CPR) factors such as a shockable initial rhythm, witnessed arrest, bystander CPR, a shorter Emergency Medical Services (EMS) response and a public location of $\mathrm{CA}^{1,7,8}$. Survival from CA decreases among aged persons after the age of 65-70. Nevertheless, age is a poor independent prognostic factor of survival with good neurological outcome $\mathrm{e}^{2,5,8-14}$. Many studies show the increasing burden of pre-arrest comorbidities to be associated with decreasing survival after $\mathrm{CA}^{8,15-19}$, while in many recent studies this association has not been found $^{5,11,13,14}$. Studies concerning the impact of nursing home $(\mathrm{NH})$ residence and functional status of the patients are even more scarce and controversial ${ }^{2,4,9,12,14,20-22}$.

EMS respond equally to all medical emergencies in Finland, including those of patients in health care facilities and aged NH residents with comorbidities. In cases of acute critical illness or emergency, patients in smaller health care facilities and NHs need to be transferred to a hospital. Occasionally, EMS is inappropriately dispatched to treat patients in health care facilities and NHs due to deficient treatment plans or lack of advance directives concerning end-of-life care ${ }^{23}$. The purpose of our study was to describe the CA patients treated by EMS in health care facilities and NHs, a subgroup that is usually excluded from either Utstein-style OHCA or in-hospital cardiac arrest (IHCA) reports. We focused specifically on patients with pre-existing do-not-attempt-resuscitation (DNAR) orders and on those patients with whom cardiopulmonary resuscitation was attempted but with efforts being promptly ceased due to evidence of medical futility ${ }^{24}$. 


\section{Materials and methods}

\section{Ethics}

We conducted an observational study with prospective data collection and post-hoc analysis. The Ethics Committee of Tampere University Hospital reviewed the study protocol (Approval no: R15048). The study was approved by Tampere University Hospital, the National Institute for Health and Welfare and the Finnish Population Register Centre. The need for patient consent was waived due to the observational nature of the study.

\section{Setting}

In the Finnish health care system, there are five university hospitals, 14 central hospitals and in addition, every municipality has a public general practitioner-level primary health care facility (PCF). The PCFs have policlinics and wards that admit patients with low-risk acute conditions, such as infections requiring intravenous antibiotics, rehabilitation after surgery, patients with terminal conditions and patients who are waiting for residency at NHs. PCFs often have an on-call physician only for phone consultations only outside office hours. Finnish patients have the right to long-term care on the basis of chronic medical conditions or decreased functional status caused by comorbidities or advanced age (over 65 years of age). Long-term care denotes both social and medical aid as needed and mainly takes place at patients' homes, but nursing homes provide long-term care for the oldest, most morbidly ill, and functionally impaired patients. NHs usually do not have any on-call physician on duty.

All acute EMS units are alarmed via a centralised emergency dispatch centre. The dispatcher makes a risk assessment based on the symptoms of the patient and defines the appropriate response. All patients with similar symptoms and similar risk analyses receive the same EMS response, regardless of whether the patient is located in a health care facility or NH. In the case of a CA patient without a DNAR order, advanced life support units are dispatched simultaneously with an anaesthetist physician-staffed Helicopter Emergency Medical Services (HEMS) unit. The purpose of this arrangement is to begin the intensive care unit-level treatment as soon as possible. Although details on the EMS, anaesthetist physician-staffed HEMS, and acute hospitals in the Pirkanmaa area were described in our previous study ${ }^{24}$, we provide a summary here. The EMS serves approximately 525,000 inhabitants. Alongside the EMS unit, the HEMS is always dispatched to a suspected CA 
patient. One HEMS unit operates in the area 24 hours a day. Patients with return of spontaneous circulation (ROSC) are transported to Tampere University Hospital.

\section{Data and definitions}

We collected all data concerning OHCAs and cardiopulmonary resuscitation attempts in the Pirkanmaa area from 1 June 2013 to 31 May 2014, according to the Utstein template ${ }^{25,26}$. This study analyses a subgroup of CPR attempts in various nursing homes and the emergency departments and wards of primary care facilities. Exclusion criteria were locations in a private residence, work place, recreational place, public place or EMS transport.

The Utstein data were prospectively collected by paramedics. We collected the additional data on patients' backgrounds and outcomes from EMS datasheets and primary care and university hospital patient records retrospectively. To evaluate the patients' prior health, we used the weighted Charlson Comorbidity Index $(\mathrm{CCI})^{27}$, which is a validated index used to predict short-term mortality. In addition, we collected data on the presence of an existing DNAR order or limitations of medical treatment from all available patient records compiled by paramedics during CPR attempts. Limitations of medical treatment were defined as limitations in providing intensive care, intubation and/or ventilator treatment, invasive procedures such as dialysis or percutaneous coronary intervention, transportation to specialised medical care facilities or allowing natural death. One author (HK) completed the data retrospectively if additional information was found during a re-check of the medical records. The dates of deaths were collected from the Finnish Population Register Centre. To describe the survival of these patients, we reported survival to hospital admission, survival to hospital discharge and 90-day survival. We also reviewed the relevant patient records to determine the neurological status of the survivors before $\mathrm{CA}$ and at hospital discharge. The neurological status was characterised by Cerebral Performance Category (CPC) as either favourable (CPC 1-2, i.e., independent) or unfavourable (CPC 3-5, i.e. dependent, comatose, brain-dead ${ }^{25}$. Futile resuscitation attempts were defined as those performed on patients with dismal chances of survival, including those with prolonged downtime, end-stage terminal illness, multiple traumas and unwitnessed asystole as the primary rhythm ${ }^{24}$. 


\section{Statistics}

Data are presented as frequencies and percentages or as median and interquartile ranges $\left(\mathrm{Q}_{1}-\mathrm{Q}_{3}\right)$. When comparing survivors and non-survivors, we used the Chi-Square test and Fisher's exact test for categorical variables and the Mann-Whitney U-test for numerical variables. $\mathrm{P}$ values $<0.05$ were considered statistically significant, and all tests were two-sided. Statistical analyses were performed using SPSS applications (IBM SPSS Statistics for Macintosh, Version 24.0 Armonk, NY: IBM Corp). 


\section{Results}

In total, $n=355$ CA patients were identified, and $n=65(18 \%)$ patients met the inclusion criteria (Figure 1). The patients included in our study were heterogeneous by their background characteristics, and mainly older than 65 with multiple comorbidities. We present the patient characteristics in Table 1. Twenty-one (32\%) CAs occurred in NHs and $n=44(68 \%)$ in PCFs. Fifteen of $n=23(65 \%) \mathrm{NH}$ residents had a DNAR order. Resuscitation was attempted on $n=38(86 \%)$ of PCF patients and $n=14$ (67\%) of NH patients ( $\mathrm{p}=0.10$, Pearson Chi-Square) (Table 2).

\section{Considered futility}

An EMS unit was dispatched to treat a CA victim with a DNAR order in $n=19$ (29\%) cases. The EMS received information about the existing DNAR order in nine of these cases (47\%), but in ten cases (53\%), the EMS did not receive this information and started CPR. Eight of the ten patients were in long-term care.

In addition to the nine patients with known DNARs, CPR attempts were discontinued due to considered futility in $n=20$ cases. The reasons for futility designation were prolonged downtime $(n=9)$, DNAR-order revealed during the resuscitation attempt $(n=5)$ or an end-state terminal disease $(n=6)$. The six (9\%) patients with diagnosed terminal illness did not have any limitations of medical treatment. HEMS physicians recognised the futility in these cases within a median of 16 minutes from dispatch $\left(\mathrm{Q}_{1}-\mathrm{Q}_{3}\right.$ 10-23) and ordered the EMS unit to terminate the resuscitation attempt. All these patients were over 87 years old except one patient, who had an old brain injury. Two of these patients did not receive bystander CPR (Table 1).

\section{Return of spontaneous circulation (ROSC) and survival after CA}

Ten patients $(n=10 ; 15 \%)$ achieved permanent ROSC. The treatment of two patients was limited after ROSC due to a dismal prognosis, and they were transferred to palliative care. Eight patients (12\%) survived to the hospital and none of them was a NH patient. The survivors were younger, were more often resuscitated at a PCF emergency department, and had had a shorter admission period in the unit where CA occurred and a shorter EMS response time (Table 1). The HEMS unit was more often present on the resuscitation attempt (i.e., not cancelled) in cases where the patient survived to hospital 
admission ( $75 \%$ for survivors vs. $12 \%$ for non-survivors, $\mathrm{p}<0.001)$, hospital discharge (100\% vs. $15 \%, \mathrm{p}=0.001)$ and 90 days after CA (100\% vs. $17 \%, \mathrm{p}=0.038)$.

Four patients admitted to the university hospital survived to hospital discharge (6\% of all 65 patients). Three patients were discharged with the same neurological status as prior to CA, and one patient remained comatose. Only two patients (3\%) were alive 90 days after CA, both with CPC 1-2. They were males under 70 years old, had ventricular fibrillation as the first monitored rhythm, and were in PCF due to an acute illness at the time of CA. 


\section{Discussion}

In this Utstein-style study, we report the results of cases in which Emergency Medical Services were dispatched to nursing homes or primary care facilities to address patients with cardiac arrest. These heterogeneous cases are normally excluded from OHCA or IHCA reports but - in this material represent $18 \%$ of EMS-treated cardiac arrests. In this study, the rate of survival after CA with a neurologically favourable outcome was 5\%. In addition, we found deficiencies in the nursing homes' and primary care facilities' resuscitation protocols $^{28}$, the most striking of which was the high proportion of patients with DNARs who received cardiopulmonary resuscitation. However, the EMS system and Helicopter Emergency Medical Services physicians seemed to recognise patients with an assumed favourable prognosis.

None of the NH residents survived in this study. Interestingly, the survival rate in our study was generally worse than survival rates reported in other recent studies investigating elderly CA patients or those living in $\mathrm{NHs}^{9,10,12-14,22}$. This could be explained by our wide inclusion criteria, as some previous studies have excluded patients with DNAR decisions or cases with unattempted resuscitation from their survival analysis ${ }^{6,11-14,21,22}$. Also, the patients in this study were older compared to the patients studied in previous reports ${ }^{1}$, which reflects the characteristics of Finnish NH residents ${ }^{29}$. As EMS responded promptly to CAs in this study, the poor survival rate can be explained mainly by the demographics of the studied patient group, although the deficiencies in the resuscitation protocol may also have had an impact on survival rates.

The most important deficiency in resuscitation protocols found in our study was that information on DNAR orders was not readily available during the resuscitation attempt. It is alarming that EMS received the DNAR information in fewer than half of the cases. Interestingly, while many of the patients with a pre-existing DNAR order underwent an inappropriate resuscitation attempt, some of the patients without a DNAR order did not receive bystander CPR, even if the CA was witnessed by a NH/PCF nurse. The proportion of DNAR patients receiving CPR was higher compared to a recent French study $(53 \% \text { vs. } 24 \%)^{30}$. We also included those cases where data on DNAR orders were accessed from medical records retrospectively, while the French study only reported the number of advance directives that EMS accessed during the CPR attempts.

Another deficiency in resuscitation protocols seen in this study was a delay in emergency dispatch calls and in the initiation of resuscitation. The longest emergency dispatch call delays (>10 min.) 
occurred in PCFs with a physician working around the clock, and the primary call to the on-call physician most likely delayed the emergency call. The longer EMS response time for non-survivors may partly explain their more dismal survival rates in our study. In contrast, the EMS system and HEMS physicians seem to recognise those patients with a favourable prognosis, as the HEMS unit was present in those CPR attempts that led to the patients' survival. Primarily, the HEMS unit is dispatched to all cardiac arrest cases, but if the physician recognises the case as futile, the physician submits a cancellation for the HEMS unit. In this study, the EMS response in the resuscitation protocol was good in general.

In addition, we found that advance directives concerning end-of-life care ${ }^{31,32}$ were often not documented. This was most obvious for patients with terminal illness. It is evident that the end-oflife-care of these patients should have been planned earlier. Finnish health care regulation states that treatment plans must be easily available and must contain patient's wishes and his/her physician's statement on intensity of treatments in case of acute illness or acceding death. ${ }^{23}$ If the end-of-life care planning fails, this leads not only to futile resuscitation attempts, but also to the absence of good palliative care when death is inevitable.

This is the first study on CA patients in NHs and PCFs treated by EMS in Finland. The study sample was small, but due to prospective recording, this study contains detailed data on all patients and the situations that occurred during the study period. Because of the small cohort, the statistical power to demonstrate differences was restricted and the results cannot be generalised without further research. Yet, the total number of beds in all locations meeting the inclusion criteria remains unknown, and we were unable to estimate the incidence of CA in this population. Our study is also limited in explaining whether the low survival rate was due to the patients' overall poor prognosis or to deficiencies in treatment. The HEMS unit was cancelled in most of the cases, which may cause selection bias, as the same reasons that lead to the poor survival of the patients often lead to the HEMS cancellation.

We conclude that CA patients in nursing homes and primary care facilities are a heterogeneous patient group. In this study, there were no CA survivors in nursing homes. Most patients with a futile prognosis could be recognised in advance. However, there were patients in primary care facilities with a good prognosis who were also well recognised by EMS. Although the prevalence of DNAR orders was reasonable, more attention should be paid to operational procedures in cases of acute deterioration of old patients with comorbidities. 


\section{Acknowledgements}

We greatly appreciate the efforts of EMS paramedics in Pirkanmaa for collecting data in the field. This research was supported by scientific research grants from the FinnHEMS Research and Development Unit; the Finnish Medical Association; the Finnish Medical Foundation; the Finnish Society of Anaesthesiologists; the fund of Doctor Uulo Arhio; and the Competitive Research Funding of the Tampere University Hospital (Grant 9S009). The funding organisations were not involved in the planning, execution, analysis or reporting of any part of the study.

\section{Conflict of interest}

The authors declare that they have no conflict of interest regarding this study.

\section{Legends to figures}

Figure 1. The inclusion and survival of patients in our study. EMS is Emergency Medical Services, ROSC is return of spontaneous circulation, DNAR is do-not-attempt-resuscitation order, and LOMT is limitations of medical treatment.

\section{REFERENCES}

1. Sasson C, Rogers MAM, Dahl J, Kellermann AL. Predictors of survival from out-of-hospital cardiac arrest: A systematic review and meta-analysis. Circulation: Cardiovascular Quality \& Outcomes 2010; 3: 63-81.

2. Deasy C, Bray JE, Smith K, Harriss LR, Bernard SA, Cameron P. Out-of-hospital cardiac arrests in the older age groups in Melbourne, Australia. Resuscitation 2011; 82: 398-403.

3. Wissenberg M, Lippert FK, Folke F, Weeke P, Hansen CM, Christensen EF, Jans H, Hansen PA, Lang-Jensen T, Olesen JB, Lindhardsen J, Fosbol EL, Nielsen SL, Gislason GH, Kober L, TorpPedersen C. Association of national initiatives to improve cardiac arrest management with rates of bystander intervention and patient survival after out-of-hospital cardiac arrest. JAMA - Journal of the American Medical Association 2013; 310:1377-84.

4. Kitamura T, Morita S, Kiyohara K, Nishiyama C, Kajino K, Sakai T, Nishiuchi T, Hayashi Y, Shimazu T, Iwami T. Trends in survival among elderly patients with out-of-hospital cardiac arrest: A prospective, population-based observation from 1999 to 2011 in Osaka. Resuscitation 2014; 85: 1432-8.

5. Søholm H, Hassager C, Lippert F, Winther-Jensen M, Thomsen JH, Friberg H, Bro-Jeppesen J, Kober L, Kjaergaard J. Factors associated with successful resuscitation after out-of-hospital cardiac arrest and temporal trends in survival and comorbidity. Ann Emerg Med 2015; 65: 52331. 
6. Wissenberg M, Folke F, Hansen CM, Lippert FK, Kragholm K, Risgaard B, Rajan S, Karlsson L, Søndergaard KB, Hansen SM, Mortensen RN, Weeke P, Christensen EF, Nielsen SL, Gislason GH, Køber L, Torp-Pedersen C. Survival after out-of-hospital cardiac arrest in relation to age and early identification of patients with minimal chance of long-term survival. Circulation 2015; 131:1536-45.

7. Rea TD, Cook AJ, Stiell IG, Powell J, Bigham B, Callaway CW, Chugh S, Aufderheide TP, Morrison L, Terndrup TE, Beaudoin T, Wittwer L, Davis D, Idris A, Nichol G, Resuscitation Outcomes Consortium Investigators. Predicting survival after out-of-hospital cardiac arrest: role of the Utstein data elements. Ann Emerg Med 2010; 55:249-57.

8. Herlitz J, Bang A, Gunnarsson J, Engdahl J, Karlson BW, Lindqvist J, Waagstein L. Factors associated with survival to hospital discharge among patients hospitalised alive after out of hospital cardiac arrest: change in outcome over 20 years in the community of Goteborg, Sweden. Heart 2003; 89:25-30.

9. van de Glind EM, van Munster BC, van de Wetering FT, van Delden, JJ, Scholten RJ, Hooft L. Pre-arrest predictors of survival after resuscitation from out-of-hospital cardiac arrest in the elderly a systematic review. BMC Geriatrics 2013; 13: 68.

10. Libungan B, Lindqvist J, Stromsoe A, Nordberg P, Hollenberg J, Albertsson P, Karlsson T, Herlitz J. Out-of-hospital cardiac arrest in the elderly: A large-scale population-based study. Resuscitation 2015; 94: 28-32.

11. Winther-Jensen M, Kjaergaard J, Hassager C, Bro-Jeppesen J, Nielsen N, Lippert FK, Kober L, Wanscher M, Soholm H. Resuscitation and post resuscitation care of the very old after out-ofhospital cardiac arrest is worthwhile. Int J Cardiol 2015; 201: 616-23.

12. Andersen LW, Bivens MJ, Giberson T, Giberson B, Mottley JL, Gautam S, Salciccioli JD, Cocchi MN, McNally B, Donnino MW. The relationship between age and outcome in out-of-hospital cardiac arrest patients. Resuscitation 2015; 94:49-54.

13. Terman SW, Shields TA, Hume B, Silbergleit R. The influence of age and chronic medical conditions on neurological outcomes in out of hospital cardiac arrest. Resuscitation 2015; 89:169-76.

14. Beesems SG, Blom MT, van der Pas, M H A, Hulleman M, van de Glind, E M, van Munster BC, Tijssen JG, Tan HL, van Delden JJ, Koster RW. Comorbidity and favorable neurologic outcome after out-of-hospital cardiac arrest in patients of 70 years and older. Resuscitation 2015; 94: 33 9.

15. Fabbri A, Marchesini G, Spada M, Iervese T, Dente M, Galvani M, Vandelli A. Monitoring intervention programmes for out-of-hospital cardiac arrest in a mixed urban and rural setting. Resuscitation 2006; 71: 180-7.

16. Carew HT, Zhang W, Rea TD. Chronic health conditions and survival after out-of-hospital ventricular fibrillation cardiac arrest. Heart (British Cardiac Society) 2007; 93:728-31.

17. Lee C, Tsai M, Fang C, Chen Y, Hui-Ming M, Huang C, Chen W, Chen S. Effects of pre-arrest comorbidities on 90-day survival of patients resuscitated from out-of-hospital cardiac arrest. Emergency medicine journal : EMJ 2011; 28:432-6

18. Jokela K, Setala P, Virta J, Huhtala H, Yli-Hankala A, Hoppu S. Using a simplified pre-hospital 'MET' score to predict in-hospital care and outcomes. Acta Anaesthesiol Scand 2015; 59: 50513.

19. Dumas F, Blackwood J, White L, Fahrenbruch C, Jouven X, Cariou A, Rea T. The relationship between chronic health conditions and outcome following out-of-hospital ventricular fibrillation cardiac arrest. Resuscitation 2017; 120:71-6.

20. Kim C, Becker L, Eisenberg MS. Out-of-hospital cardiac arrest in octogenarians and nonagenarians. Arch Intern Med 2000; 160:3439-43. 
21. Abbo ED, Yuen TC, Buhrmester L, Geocadin R, Volandes AE, Siddique J, Edelson DP. Cardiopulmonary resuscitation outcomes in hospitalized community-dwelling individuals and nursing home residents based on activities of daily living. J Am Geriatr Soc 2013; 61:34-9.

22. Søholm H, Bro-Jeppesen J, Lippert FK, Kober L, Wanscher M, Kjaergaard J, Hassager C. Resuscitation of patients suffering from sudden cardiac arrests in nursing homes is not futile. Resuscitation 2014; 85: 369-75.

23. Sosiaali- ja terveysalan lupa- ja valvontavirasto, VALVIRA. Hoitosuunnitelmat ja DNR-päätös pitkäaikaishoidossa ja ensihoito [Treatment plans and DNAR decisions in long-term care facilities and emergency medicine service.] 2015.

24. Setälä P, Hoppu S, Virkkunen I, Yli-Hankala A, Kämäräinen A. Assessment of futility in out-ofhospital cardiac arrest. Acta Anaesthesiol Scand 2017; 61: 1334-44.

25. Cummins RO, Chamberlain DA, Abramson NS, Allen M, Baskett PJ, Becker L, Bossaert L, Delooz HH, Dick WF, Eisenberg MS. Recommended guidelines for uniform reporting of data from out-of-hospital cardiac arrest: the Utstein Style. A statement for health professionals from a task force of the American Heart Association, the European Resuscitation Council, the Heart and Stroke Foundation of Canada, and the Australian Resuscitation Council. Circulation 1991; 84: $960-75$.

26. Jacobs I, Nadkarni V, Bahr J, Berg RA, Billi JE, Bossaert L, Cassan P, Coovadia A, D'Este K, Finn J, Halperin H, Handley A, Herlitz J, Hickey R, Idris A, Kloeck W, Larkin GL, Mancini ME, Mason P, Mears G, Monsieurs K, Montgomery W, Morley P, Nichol G, Nolan J, Okada K, Perlman J, Shuster M, Steen PA, Sterz F, Tibballs J, Timerman S, Truitt T, Zideman D. Cardiac arrest and cardiopulmonary resuscitation outcome reports: Update and simplification of the Utstein templates for resuscitation registries. A statement for healthcare professionals from a task force of the international liaison committee on resuscitation. Resuscitation 2004; 63: 23349.

27. Charlson ME, Pompei P, Ales KL, MacKenzie CR. A new method of classifying prognostic comorbidity in longitudinal studies: Development and validation. J Chronic Dis 1987; 40: 37383.

28. Monsieurs KG, Nolan JP, Bossaert LL, Greif R, Maconochie IK, Nikolaou NI, Perkins GD, Soar J, Truhlár A, Wyllie J, Zideman DA, Abbas Khalifa GE, Alfonzo A, Arntz H-, Askitopoulou H, Bellou A, Beygui F, Biarent D, Bingham R, Bierens, J J L M, Böttiger BW, Brattebø G, Brugger H, Bruinenberg J, Cariou A, Carli P, Castren M, Cassan P, Chalkias AF, Conaghan P, Deakin CD, De Buck, E D J, Dunning J, Evans TR, Vries WD, Eich C, Gräsner J-, Hafner CM, Handley AJ, Hunyadi-Anticevic S, Haywood KL, Koster RW, Lippert A, Lockey DJ, Lockey AS, Lópezherce J, Lott C, Mentzelopoulos SD, Meyran D, Monsieurs K-G, Olasveengen T, Paal P, Pellis T, Rajka T, Raffay VI, Ristagno G, Rodríguez-Núñez A, Roehr CC, Rüdiger M, SchunderTatzber S, Sandroni C, Singletary EM, Skrifvars MB, Smith GB, Smyth MA, Thies K-, Trevisanuto D, Vandekerckhove PG, Van de Voorde P, Sunde K, Wenzel V, Urlesberger B, Xanthos TT. European Resuscitation Council Guidelines for Resuscitation 2015. Section 1. Executive summary. Resuscitation 2015; 95: 1-80.

29. Vanttaja K, Seinelä L, Valvanne J. Elämän loppuvaiheen sairaalasiirrot ja hoidon suunnittelu tehostetussa palveluasumisessa Tampereella 2011 [Hospital transferrings and treatment planning at the end of life in skilled nursing facilities in Tampere 2011]. Gerontologia 2015; 29: 61-74.

30. Reuter P, Agostinucci J, Bertrand P, Gonzalez G, De Stefano C, Hennequin B, Nadiras P, Biens D, Hubert H, Gueugniaud P, Adnet F, Lapostolle F. Prevalence of advance directives and impact on advanced life support in out-of-hospital cardiac arrest victims. Resuscitation 2017; 116: 1058.

31. Bossaert LL, Perkins GD, Askitopoulou H, Raffay VI, Greif R, Haywood KL, Mentzelopoulos SD, Nolan JP, Van de Voorde P, Xanthos TT, Georgiou M, Lippert FK, Steen PA. European 
Resuscitation Council Guidelines for Resuscitation 2015. Section 11. The ethics of resuscitation and end-of-life decisions. Resuscitation 2015; 95: 302-11.

32. Cardona-Morrell M, Chapman A, Turner RM, Lewis E, Gallego-Luxan B, Parr M, Hillman K. Pre-existing risk factors for in-hospital death among older patients could be used to initiate endof-life discussions rather than Rapid Response System calls: A case-control study. Resuscitation 2016; 109: 76-80. 
Table1 EM S units encountered cardiac arrest patients in nursing homes and primary care facilities during one year in the Pirkanmaa area. The table shows detailed information on demographics of patients and resuscitation attempts.

\begin{tabular}{|c|c|c|c|c|c|c|c|}
\hline \multirow{2}{*}{$\begin{array}{l}\text { Patient demographics, detailed information } \\
\text { on } C A^{a} \text { situation and } C P R^{b} \text {. }\end{array}$} & \multicolumn{2}{|c|}{ All } & \multicolumn{2}{|c|}{ Survived to hospital } & \multicolumn{2}{|c|}{ Deceased on scene } & \multirow[b]{2}{*}{$\mathrm{p}$} \\
\hline & $n=65$ & & $n=8$ & & $n=57$ & & \\
\hline Age, years & & & & & & & \\
\hline Median (Q1-Q3) & 82 & $(68-90)$ & 70 & $(62-82)$ & 84 & $(70-90)$ & $* * 0.03$ \\
\hline M ale median (Q1-Q3) & 77 & $(67-87)$ & 64 & $(52-76)$ & 80 & $(70-88)$ & $* * 0.03$ \\
\hline Female median (Q1-Q3) & 88 & $(75-91)$ & 83 & - & 88 & $(72-91)$ & $* * 0.49$ \\
\hline Male gender $n(\%)$ & 36 & (55) & 6 & (75) & 30 & (53) & $* 0.28$ \\
\hline Physical performance $\mathrm{n}(\%)$ & & & & & & & 0.33 \\
\hline Outdoor independence & 16 & (29) & 1 & (13) & 15 & (32) & \\
\hline In-house independence & 26 & (47) & 6 & (75) & 20 & (43) & \\
\hline Dependent on assistance & 13 & (24) & 1 & (13) & 12 & (26) & \\
\hline Impaired Cognition $n(\%)$ (missing $n=10)$ & 28 & (51) & 4 & (57) & 24 & (50) & 1.00 \\
\hline CCl scored, median, (Q1-Q3) & 4 & $(3-6)$ & 3 & $(2-4.8)$ & 4 & $(3-6)$ & $* * 0.25$ \\
\hline $\mathrm{CCl} \geq 3 \mathrm{n}(\%)$ & 46 & (78) & 5 & (63) & 41 & (80) & $* 0.36$ \\
\hline Independent living $n(\%)$ (missing $n=3$ ) & 21 & (34) & 2 & (25) & 19 & (35) & 0.71 \\
\hline In institutional LTCe $\mathrm{n}(\%)$ & 23 & (37) & 0 & (0) & 23 & (43) & 0.02 \\
\hline Days spent at current location prior $\mathrm{CA}^{\mathrm{f}}$ & & & & & & & 0.04 \\
\hline $0-1$ & 15 & (28) & 5 & (63) & 10 & (22) & \\
\hline $2-7$ & 16 & (30) & 3 & (38) & 13 & (28) & \\
\hline $8-90$ & 10 & (19) & 0 & (0) & 10 & (22) & \\
\hline over 90 & 13 & (24) & 0 & (0) & 13 & (28) & \\
\hline Arrest location n (\%) & & & & & & & 0.002 \\
\hline Primary care emergency department & 7 & (11) & 4 & (50) & 3 & (5) & \\
\hline Primary care hospital ward & 37 & (57) & 4 & (50) & 33 & (58) & \\
\hline Nursing home & 21 & (32) & 0 & $(0)$ & 21 & (37) & \\
\hline Existing DNAR ${ }^{g} \mathrm{n}(\%)$ & 19 & (29) & 0 & (0) & 19 & (33) & 0.09 \\
\hline DNAR, resuscitation attempted & 10 & (53) & 0 & (0) & 10 & (53) & \\
\hline Witnessed arrest n (\%) & 53 & (82) & 8 & (100) & 45 & (79) & $* 0.33$ \\
\hline Arrest after arrival of EM S n (\%) & 12 & (18) & 3 & (38) & 9 & (16) & 0.16 \\
\hline Bystander CPR ${ }^{\mathrm{h}}, \mathrm{n}(\%)$ & 43 & (81) & 5 & (100) & 38 & (79) & $* 0.57$ \\
\hline No existing DNAR, no bystander CPR & 2 & (4) & 0 & $(0)$ & 2 & (5) & \\
\hline Presumed cardiac aetiology $n(\%)$ & 53 & (82) & 5 & (63) & 48 & (84) & $* 0.16$ \\
\hline First monitored rhythm $\mathrm{n}(\%)$ & & & & & & & 0.16 \\
\hline VF/pulseless VT/AED-shockable & 13 & (20) & 3 & (38) & 10 & (18) & \\
\hline PEA/AED non-shockable & 22 & (34) & 3 & (38) & 19 & (33) & \\
\hline Asystole & 26 & (40) & 1 & (13) & 25 & (44) & \\
\hline Other & 4 & (6) & 1 & (13) & 3 & (5) & \\
\hline Time intervals, median, minutes (Q1-Q3) & & & & & & & \\
\hline Collapse-to-calli & 2 & $(0-8)$ & 2 & $(0.5-15.5)$ & 2 & $(0-8)$ & $* * 0.46$ \\
\hline Call-to-EM S arrival & 7 & $(5-10.5)$ & 4 & $(1.75-7)$ & 7 & $(5-11.5)$ & $* * 0.006$ \\
\hline Collapse-to-ROSC & 15 & $(7-33.5)$ & 17 & $(7-39.8)$ & 13 & $(13-13)$ & $* * 0.89$ \\
\hline Beginning-of -to-end-of EM S CPR & 9 & $(1-19)$ & 9 & $(3.3-22.8)$ & 9 & $(0-19)$ & $* * 0.82$ \\
\hline Any ROSC n (\%) & 23 & (35) & 8 & $(100)$ & 15 & (26) & $*<0.001$ \\
\hline HEM Sk on scene $n(\%)$ & 13 & $(20)$ & 6 & (75) & 7 & (12) & $*<0.001$ \\
\hline Treatment withdrawn n (\%) & & & & & & & $\varangle .001$ \\
\hline On field & 31 & (48) & 1 & (13) & 30 & (53) & \\
\hline In hospital emergency department & 3 & (5) & 3 & (38) & 0 & $(0)$ & \\
\hline No limitation of medical treatment & 31 & (48) & 4 & (50) & 27 & (47) & \\
\hline
\end{tabular}




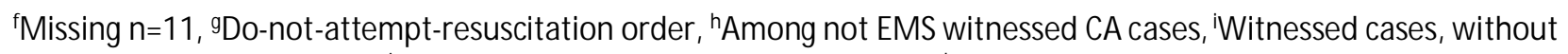

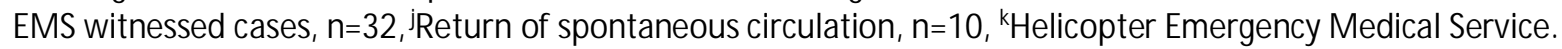
Impaired cognition: Patient with diagnosed dementia of any cause, M ini-M ental State Examination score $<24$, moderate or severe intellectual disability or severe skitsofrenia with residence in NH. P values marked with * are calculated with Pearson Chi-square test and with** are calculated with the M ann-Whitney U-test, and the others are calculated with the Fisher exact test. 
Table2. The survival rates of cardiac arrest patients with attempted cardiopulmonary resuscitation grouped by the location of the patient in primary health care facility (PCF) or in nursing home (NH). All patients were resuscitated by an EM S unit in the Pirkanmaa area during one year. LOMT is limitations of medical treatment. P-values are calculated with Fisher's test.

\begin{tabular}{|c|c|c|c|c|c|c|}
\hline \multirow[t]{2}{*}{$\begin{array}{l}\text { Survival rates of patients with } \\
\text { cardiopulmonary resuscitation attempted }\end{array}$} & \multicolumn{2}{|c|}{$\begin{array}{c}\text { All patients } \\
n=52\end{array}$} & \multicolumn{2}{|c|}{$\begin{array}{l}\text { PCF } \\
n=38\end{array}$} & \multicolumn{2}{|c|}{$\begin{array}{c}\mathrm{NH} \\
\mathrm{n}=14\end{array}$} \\
\hline & $\mathrm{n}$ & $\%$ & $\mathrm{n}$ & $\%$ & $\mathrm{n}$ & $\%$ \\
\hline Any return of spontaneous circulation & 22 & 42 & 21 & 55 & 1 & 7 \\
\hline Survival to hospital & 8 & 15 & 8 & 22 & 0 & 0 \\
\hline LOM T in hospital Emergency Department & 3 & 6 & 3 & 8 & 0 & 0 \\
\hline Survival to hospital discharge & 4 & 8 & 4 & 11 & 0 & 0 \\
\hline 90-day survival & 2 & 4 & 2 & 5 & 0 & 0 \\
\hline
\end{tabular}


All EMS dispatched cardiac arrest patients in the

Pirkanmaa area during one year

$n=355$

Location in nursing home or primary care facility

$$
n=65
$$

Location at home, public place, or transport. Excluded from present study $n=290$

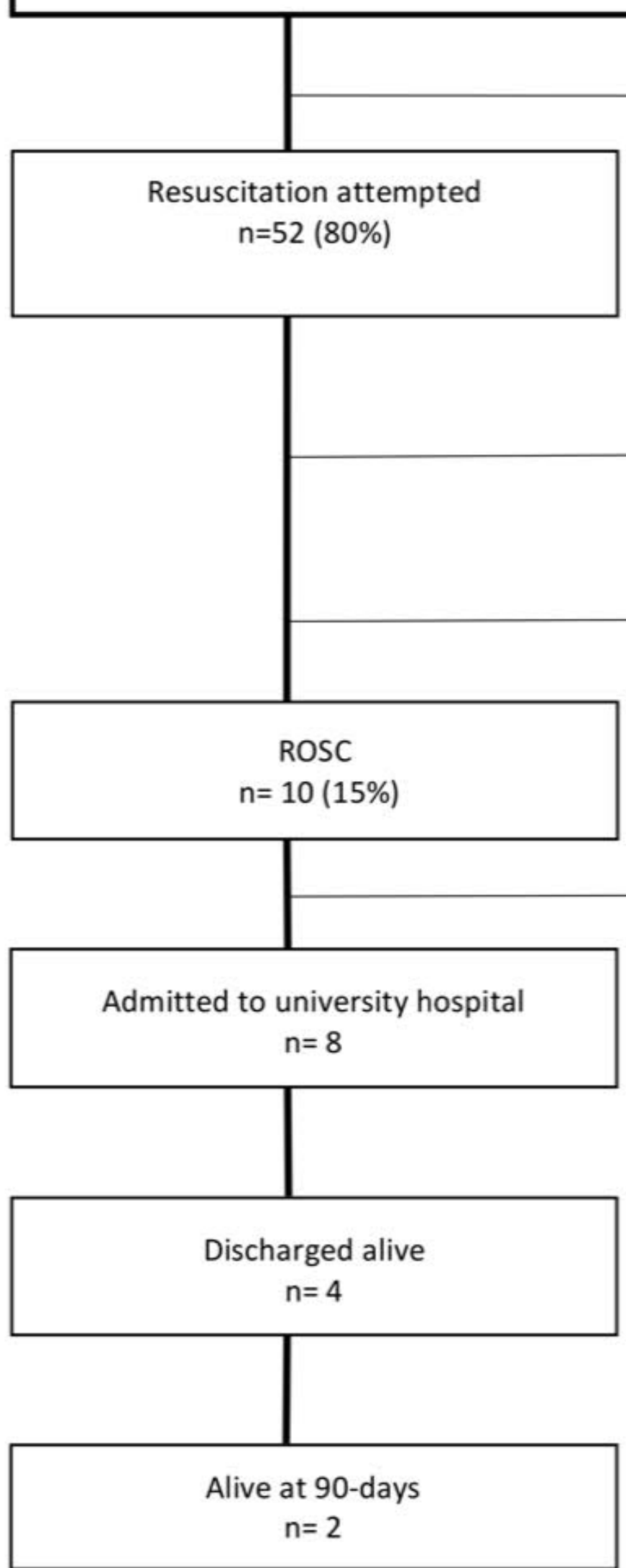

\section{Resuscitation not attempted} $n=13(20 \%)$

Known DNAR $n=9$

Futility revealed during resuscitation attempt

$n=18(28 \%)$

Full resuscitation attempt $n=24(37 \%)$
LOMT and transfer to palliative care $n=2$ 